\title{
MODIFIED VARIABLE ON-TIME CONTROL SCHEME TO REALIZE HIGH POWER FACTOR FOR AC/DC INTEGRATED BUCK-BOOST CONVERTER
}

\section{Abdul Hakeem Memon \\ Institute of Information and Communication Technologies (IICT), \\ Mehran UET, Jamshoro, Sindh, (Pakistan). \\ E-mail: hakeem.memon@faculty.muet.edu.pk \\ ORCID: https://orcid.org/0000-0001-8545-3823}

Nazia Memon

Institute of Information and Communication Technologies (IICT),

Mehran UET, Jamshoro, Sindh, (Pakistan).

E-mail: naziamemon52@gmail.com

ORCID: https://orcid.org/0000-0003-2919-9220

Zubair Ahmed Memon

Institute of Information and Communication Technologies (IICT),

Mehran UET, Jamshoro, Sindh, (Pakistan).

E-mail: zubair.memon@faculty.muet.edu.pk

ORCID: https://orcid.org/0000-0001-5967-3152

\section{Citación sugerida:}

Memon, A. H., Memon, N., y Memon, Z. A. (2021). Modified variable on-time control scheme to realize high power factor for AC/DC integrated buck-boost converter. 3C Tecnología. Glosas de innovación aplicadas a la pyme, Edición Especial, (mayo 2021), 67-81. https://doi.org/10.17993/3ctecno.2021. specialissue7.67-81 


\section{ABSTRACT}

In today's modern era low power factor $(\mathrm{PF})$ is major issue in the field of power electronics which has made our life, simpler, easier and comfortable. However, with this comfort and easiness this technology brings power quality issues because it is centered on solid-state devices. These issues introduce harmonic contained current or distorted current which has several drawbacks like high power loss, voltage distortion and EMI compatibility issues etc. The conventional boundary conduction mode (BCM) integrated buck-boost converter (BBC) operating with constant on-time control (COT) control scheme have low PF with high total harmonic distortion (THD) because of harmonic contained input current waveform. So, in order to make the input current waveform as a sinusoidal by changing the on-time of only buck switch, a modified variable-on-time (VOT) control scheme for Integrated BBC is proposed in this paper. The VOT control scheme can achieve high PF with low THD by utilizing the input and output voltage to modulate the on-time of only buck switch. The theoretical analysis is given, and the simulation results confirm the advantages of the proposed control scheme. The object of the research paper is to propose the control scheme to realize unity PF for CRM buck converter by only modulating the on-time of buck switch. The research methodology is based on: Input PF analysis of buck converter with traditional control scheme; Introduction of proposed control scheme; comparative analysis and simulation results to show the effectiveness of proposed control scheme.

\section{KEYWORDS}

Buck-Boost Converter (BBC), Constant On-Time Control (COT), Variable-On-Time (VOT), Power Factor (PF), Total Harmonic Distortion (THD), Electromagnetic Interference (EMI). 


\section{INTRODUCTION}

Power electronic technology is employed in various sorts of modern equipment's which has made our life, simpler, easier and comfortable. However, with this comfort and easiness this technology brings power quality issues because it is centered on solid-state devices. These issues introduce harmonic contained current or distorted current which has several drawbacks like high power loss, voltage distortion and EMI compatibility issues etc. Therefore, the standards are set by various industrious like IEC61000-3-2 limit and IEEE 519 (IEC Standard, 61000-3, n.d.); Langella, Testa, \& Alii, 2014) to limit these harmonics. In order to meet relevant harmonic standard and reducing input current distortion, various researchers have proposed different types of power factor correction $(\mathrm{PFG})$ converters (García et al., 2003; Singh et al., 2011; Memon et al., 2016; Memon et al., 2018a, 2018b; Memon et al., 2019a, 2019b, 2019c, 2019d, 2019e; Memon et al., 2020a, 2020b, 2020c). The DC/DG converters or choppers such as buck, boost and buck-boost etc. are normally employed for PFG application.

Each converter has its own advantages and disadvantages. The boost converter is good selection for PFG due to various advantages like high PF, less current ripples and high efficiency (Yang et al., 2011), However, its efficiency is low at low input line due to use of more duty-cycle when the input is $90 \mathrm{Vrms}$ and the output is $400 \mathrm{~V}$. The buck-boost converter can step up or step down the input voltage and its characteristics are better as compared to SEPIC, Flyback and CUK converter. However, its efficiency is low, voltage and current stress is more compared to boost and buck converter because the energy of output is charged from inductor (Chen \& Maksimović, 2010; Hwang \& Park, 2012).

The buck converter now days have attracted the attention of the many researchers (Mahdavi \& Farzanehfard, 2010; Liu et al., 2014; Wu et al., 2011; Wu et al., 2012; Memon et al., 2016; Memon et al., 2018a, 2018b; Memon et al., 2019a, 2019b, 2019c, 2019d, 2019e; Liu et al., 2020). It can maintain high efficiency at all input voltages. It also offers other advantages like cost reduction, low output voltage, protection against inrush current, low stress on the switch and life time improvement. 
The input PF of buck converter in low because of dead zone in the average input current that is present until input voltage is more than output voltage. It causes the input current to contain large harmonic disturbances.

For modifying the performance of buck converter, various researchers have proposed various techniques and control schemes. Many research attempts have been conducted to improve the performances of the conventional buck PFC converter (Mahdavi \& Farzanehfard, 2010; Liu et al., 2014; Wu et al., 2011; Wu et al., 2012; Memon et al., 2016; Memon et al., 2018a, 2018b; Memon et al., 2019a, 2019b, 2019c, 2019d, 2019e; Liu et al., 2020).

This paper is divided into six sections. In section 2, the operation states of BCM IBBC are analyzed with traditional constant on-time control scheme (COTCS). The introduced VOTCS is discussed in section 3. Then the comparative analysis is discussed in section 4 in terms of PF. In section 5, the effectiveness of proposed topology is evaluated by simulation results. Finally, some conclusions are drawn in section 6.

\section{RESEARCH METHODOLOGY}

The research methodology is based on:

1. Mathematical analysis of the operating principle of the traditional control scheme for BCM IBBC with the help of MATHCAD software.

2. Analysis of input PF of BCM integrated BBC.

3. Introducing the proposed control scheme to obtain high PF with low THD.

4. Comparative analysis of the converter for COT control scheme and VOT control scheme strategy in terms of input PF and THD.

5. Developing the simulation model of the converter with traditional and proposed control scheme with the help of MATLAB software.

6. Confirming the results. 


\section{CONVENTIONAL COTCS FOR BCM IBBC}

Figure 1 shows the main circuit of the IBBC. It is a buck converter in series with a boost converter with a common inductor. It works in buck mode with the boost switch opened when the instantaneous input line voltage is higher than the boundary voltage and otherwise in boost mode with buck switch closed. The boundary voltage is set a little higher than the output voltage. The converter operates in BCM and its working principle can be analyzed in two cases.

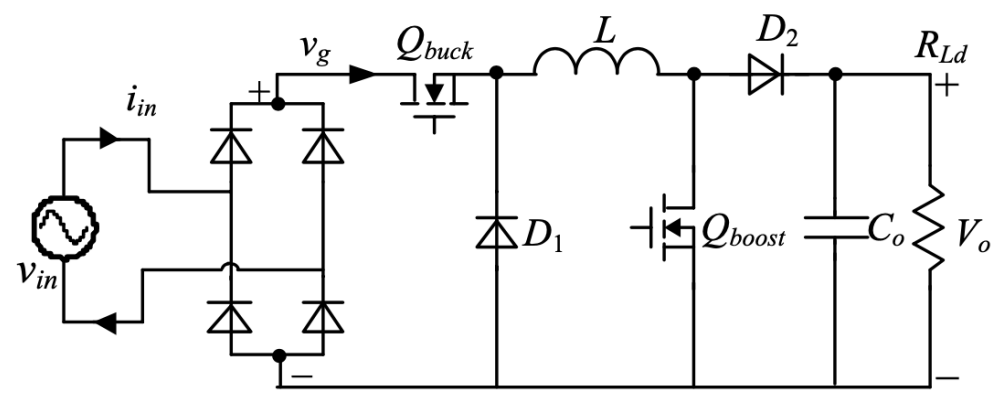

Figure 1. Schematic Diagram of IBBC.

Source: (Memon et al., 2019).

The input voltage and rectified input voltage is expressed as

$$
\begin{gathered}
v_{i n}(\theta)=\sqrt{2} V_{r m s} \sin \theta \\
v_{g}=\sqrt{2} V_{r m s}|\sin \theta|
\end{gathered}
$$

where $V_{r m s}$ is the rms value

The IBBC is working in buck mode until input voltage is more than boundary voltage.

Thus $Q_{\text {puck }}$ is operating while $Q_{\text {bost }}$ is off

When buck switch is on, the inductor voltage is expressed as

$$
L \frac{d i_{L}}{d t}=\sqrt{2} V_{r m s}|\sin \theta|-V_{o}\left(\theta_{0} \leq \theta \leq \pi-\theta_{0}\right)
$$

where $\theta_{0}=\arcsin \frac{V_{\text {boundary }}}{\sqrt{2} V_{r m s}}$

So its peak value is 


$$
i_{L(p k)}(\theta)=\frac{\sqrt{2} V_{r m s}|\sin \theta|-V_{o}}{L} t_{o n}
$$

where $t_{o n}$ is the on-time of the switch.

While $Q_{\text {buck }}$ is off, the inductor is discharged through load.

$$
-L \frac{d i_{L}}{d t}=V_{o}
$$

For each switching cycle, the value of off-time is calculated from inductor's volt-second balance

$$
t_{o f f}=\frac{L}{V_{o}} i_{L(p k 1)}(\theta)
$$

From (3) and (5), the following relation is obtained

$$
t_{o f f}=\frac{\sqrt{2} V_{r m s}|\sin \theta|-V_{o}}{V_{o}} t_{o n}
$$

In addition

$$
t_{s}=t_{o n}+t_{o f f}
$$

Substituting (6) into (7)

$$
t_{s}=\left(\frac{\sqrt{2} V_{r m s}|\sin \theta|}{V_{o}}\right) t_{o n}
$$

The value of average input current for buck converter is got from

$$
i_{\text {buck(arg) }}(\theta)=\frac{i_{L(p k l)}(\theta) t_{o n}}{2 t_{s}}
$$

Substituting (3) and (8) into (9)

$$
i_{\text {buck (ang) }}(\theta)=\frac{t_{o n} V_{o}}{2 L}\left(\frac{\sqrt{2} V_{\text {mos }}|\sin \theta|-V_{o}}{\sqrt{2} V_{\text {rms }}|\sin \theta|}\right)
$$

The IBBC is working in boost mode until input voltage is less than boundary voltage. Thus $Q_{\text {boost }}$ is operating while $Q_{\text {ouck }}$ is off

When boost switch is on, the inductor voltage is given as

$$
i_{L(p k 2)}(\theta)=\frac{\sqrt{2} V_{r m s}|\sin (\theta)|}{L} t_{o n}
$$


Same as (6), for each switching cycle, the value of off-time is calculated from inductor's volt-second balance

$$
t_{\text {off }}=\frac{\sqrt{2} V_{r m s}|\sin (\theta)|}{V_{o}-\sqrt{2} V_{r m s}|\sin (\theta)|} t_{o n}
$$

Substituting (13) into (8), we get

$$
t_{s}=\left(\frac{V_{o}}{V_{o}-\sqrt{2} V_{r m s}|\sin (\theta)|}\right) t_{o n}
$$

The value of average input current for boost converter is determined as

$$
i_{\text {boost(avg) }}(\theta)=\frac{i_{L(p k 2)}(\theta)}{2}
$$

Combining (12) and (14), we get

$$
i_{\text {boost (avg) }}(\theta)=\frac{\sqrt{2} V_{\text {rms }}|\sin (\theta)|}{2 L} t_{\text {on }}
$$

Based on above analysis, the average input current of the IBBC with COTCS is as following.

$$
i_{\text {in }_{-} \text {COTCS }}(\theta)= \begin{cases}\frac{\sqrt{2} V_{r m s}}{2 L}|\sin \theta| t_{\text {on }} & \left(0 \leq \theta<\theta_{0} \& \pi-\theta_{0}<\theta \leq \pi\right) \\ \frac{t_{o n} V_{o}}{2 L}\left(\frac{\sqrt{2} V_{r m s}|\sin \theta|-V_{o}}{\sqrt{2} V_{r m s}|\sin \theta|}\right)\left(\theta_{0} \leq \theta \leq \pi-\theta_{0}\right)\end{cases}
$$

Based on (1) and (16), The input power of the IBBC is expressed as

$$
P_{\text {inc(COTCS })}=\frac{t_{\text {on }}}{2 \pi L}\left[2 \int_{0}^{\theta_{0}}\left(\sqrt{2} V_{r m s}|\sin \theta|\right)^{2} d \theta+\int_{\theta_{0}}^{\pi-\theta_{0}} V_{o}\left(\sqrt{2} V_{r m s}|\sin \theta|-V_{o}\right) d \theta\right]
$$

Now $t_{o n}$ can be calculated by assuming the efficiency of IBBC as $100 \%$

$$
t_{o n}=\frac{2 \pi P_{o} L}{\left[2 \int_{0}^{\theta_{0}}\left(\sqrt{2} V_{r m s}|\sin \theta|\right)^{2} d \theta+\int_{\theta_{0}}^{\pi-\theta_{0}} V_{o}\left(\sqrt{2} V_{r m s}|\sin \theta|-V_{o}\right) d \theta\right]}
$$

And input power factor can be calculated as

$$
P F=\frac{P_{i n}}{V_{r m s} I_{r m s}}
$$

Based on (16-20) and specification, the curve of the input $\mathrm{PF}$ can be drawn and is given in Figure 2 from which it can be observed that the input $\mathrm{PF}$ is not unity for the wide range of the input voltage. 


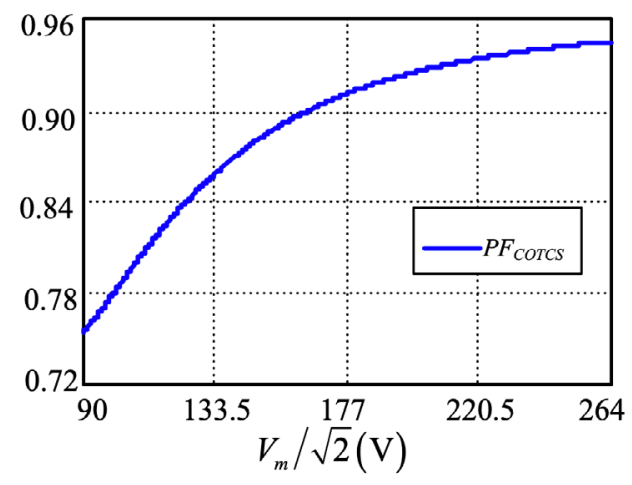

Figure 2. Input PF of COTCS [Eq: 17 to 20; Using Mathcad software].

\section{PROPOSED VOTCS FOR BCM IBBC}

For obtaining unity PF for the buck converter, the on-time of $Q_{\text {buck }}$ in (11) should vary as

$$
t_{o n(b u c k)}=k_{o n 1} \frac{\left(\sqrt{2} V_{r m s}|\sin \theta|\right)^{2}}{V_{o}\left(\sqrt{2} V_{r m s}|\sin \theta|-V_{o}\right)}
$$

where $k_{\text {onl }}$ is a constant

Substituting (21) into (11), the average input current of the buck converter is

$$
i_{\text {buck (avg) }}(\theta)=\frac{\sqrt{2} V_{\text {rms }}|\sin \theta|}{2 L} k_{\text {on1 }}\left(\theta_{0} \leq \theta \leq \pi-\theta_{0}\right)
$$

From (22), it can be seen that if the on-time of the buck converter varies as (21), the input current waveform looks like pure sinusoidal and the $\mathrm{PF}$ is unity

From (16), it is clear that the input current of the boost converter is already sinusoidal. So there is no need of the variation of the on-time of the $Q_{\text {boost }}$

$$
i_{\text {boost (avg) }}(\theta)=\frac{\sqrt{2} V_{\text {rms }}|\sin (\theta)|}{2 L} k_{\text {on } 2} \quad\left(0 \leq \theta<\theta_{0} \& \pi-\theta_{0}<\theta \leq \pi\right)
$$

$k_{o n 2}$ is a constant.

The average input current of the IBBC with VOTCS is 


$$
i_{\text {in_ } \_ \text {OOTCS }}(\theta)= \begin{cases}\frac{k_{\text {on2 } 2} \sqrt{2} V_{r m s}|\sin \theta|}{2 L} & \left(0 \leq \theta<\theta_{0}\right) \&\left(\pi-\theta_{0}<\theta \leq \pi\right) \\ \frac{k_{o n 1} \sqrt{2} V_{r m s}|\sin \theta|}{2 L} & \left(\theta_{0} \leq \theta \leq \pi-\theta_{0}\right)\end{cases}
$$

Because of the power balance of the input and output, the input current for the unity PF can be expressed as

$$
i_{i n}(\theta)=\frac{\sqrt{2} P_{o}|\sin \theta|}{V_{r m s}}
$$

Based on (25-26), the input current at $\boldsymbol{\theta}_{0}$ can be written as

$$
i_{i n}\left(\theta_{0}\right)=\frac{k_{\text {on } 1} \sqrt{2} V_{r m s}\left|\sin \theta_{0}\right|}{2 L}=\frac{k_{\text {on } 2} \sqrt{2} V_{r m s}\left|\sin \theta_{0}\right|}{2 L}=\frac{\sqrt{2} P_{o}\left|\sin \theta_{0}\right|}{V_{r m s}}
$$

From (26), it can be concluded that

$$
\begin{aligned}
& k_{o n 1}=\frac{2 P_{o} L}{V_{r m s}^{2}} \\
& k_{o n 2}=\frac{2 P_{o} L}{V_{r m s}^{2}}
\end{aligned}
$$

From (27-28) it can be summarized as $k_{o n 1}=k_{o n 2}=k_{o n}$ Hence, the input current of the IBBC with VOTCS is

$$
i_{\text {in__OTCS }}(\theta)= \begin{cases}\frac{k_{\text {on }} \sqrt{2} V_{\text {rms }}|\sin \theta|}{2 L} & \left(0 \leq \theta<\theta_{0}\right) \&\left(\pi-\theta_{0}<\theta \leq \pi\right) \\ \frac{k_{\text {on }} \sqrt{2} V_{\text {rms }}|\sin \theta|}{2 L} & \left(\theta_{0} \leq \theta \leq \pi-\theta_{0}\right)\end{cases}
$$

Equation (29) demonstrates that input current of IBBC with VOTCS is pure sinusoidal. Thus unity PF can be realized by using proposed control scheme.

\section{COMPARATIVE ANALYSIS}

From (14), the input PF curve with proposed control scheme is shown in Figure 3 which also includes the PF values with traditional control scheme of Figure 2. It can be concluded that the $\mathrm{PF}$ of the converter with proposed control is higher as compared to COTC. The values 
of input PF for COTCS \& VOTCS along with percentage improvement is written in Table 1. It can conclude that improvement at low line is more as compared to high line.

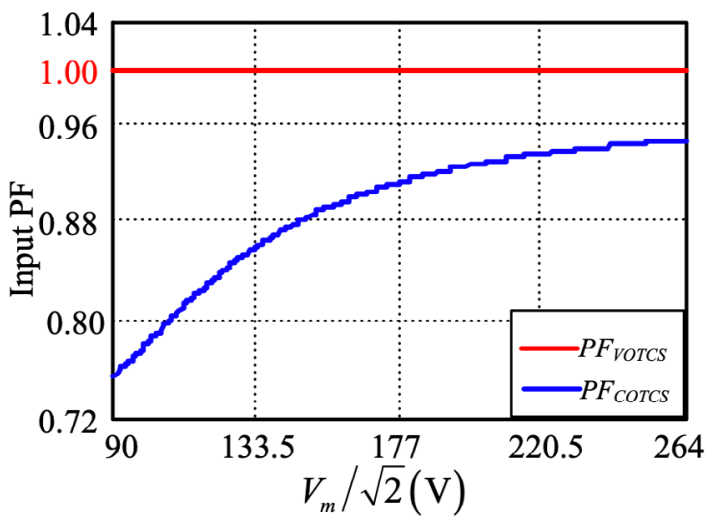

Figure 3. Input PF comparison between COTCS \& VOTCS [Eq: 17 to 20 \& 22 to 29 ; Using Mathcad software].

Table 1. Input PF comparison between COTCS \& VOTCS [Eq: 17 to 20 \& 22 to 29; Using Mathcad software].

\begin{tabular}{|c|c|c|c|c|}
\hline S. No & Input Voltage & PF(COTCS) & PF(VOTCS) & \% Improvement \\
\hline 1 & $90 V_{r m s}$ & 0.755 & 1 & 32.499 \\
\hline 2 & $110 V_{r m s}$ & 0.807 & 1 & 23.887 \\
\hline 3 & $130 V_{r m s}$ & 0.852 & 1 & 17.309 \\
\hline 4 & $150 V_{r m s}$ & 0.884 & 1 & 13.14 \\
\hline 5 & $170 V_{r m s}$ & 0.905 & 1 & 10.485 \\
\hline 6 & $190 V_{r m s}$ & 0.920 & 1 & 8.737 \\
\hline 7 & $210 V_{r m s}$ & 0.93 & 1 & 7.55 \\
\hline 8 & $230 V_{r m s}$ & 0.937 & 1 & 6.723 \\
\hline 9 & $250 V_{r m s}$ & 0.942 & 1 & 6.136 \\
\hline 10 & $264 V_{r m s}$ & 0.945 & 1 & 5.827 \\
\hline
\end{tabular}

\section{SIMULATION RESULTS}

In order to verify the effectiveness of VOT control scheme, simulations results are given. The range of input voltage is $90-264 V_{r m s}$. The output voltage is selected as $90 \mathrm{~V}$. The control IC 6561 will ensure the current to be in BCM. Ideal components are used in simulation

Figure 4 illustrates the waveforms of input voltage and boundary voltage versus gate drive signal of integrated BBC. It indicates only one converter is conducting at a time depending on the boundary voltage. 


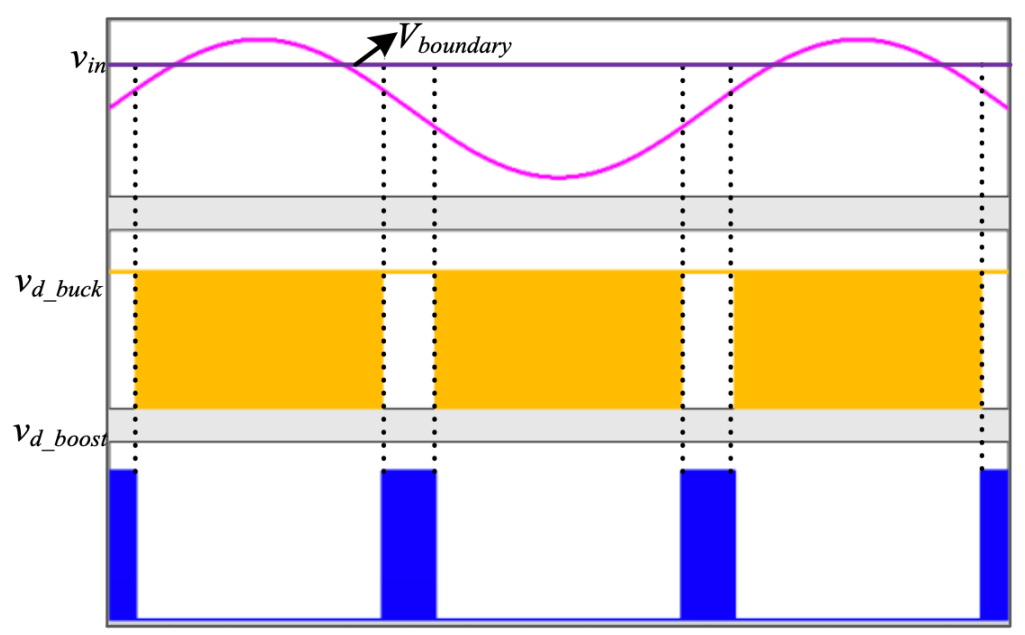

Figure 4. $V_{i n}, V_{d \_b u c k}$ and $V_{d \_b o o s t}[$ Saber software].

Figure 5 and Figure 6 show the simulation waveforms of $v_{i n}$, \& $i_{i n}$ of integrated BBC with COT control scheme and VOT control scheme at 220VAC inputs, respectively. It can be conducted that current is almost sinusoidal in case of VOTCS as compared to COTCS. Thus, VOTGS can attain unity PF.

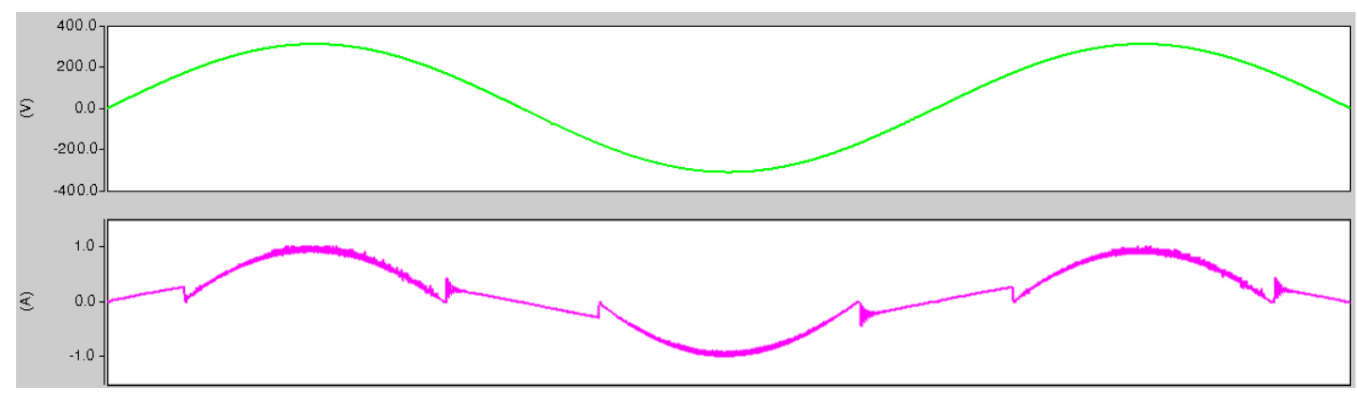

Figure 5. Input voltage and current of IBBC with COTCS [Saber software].

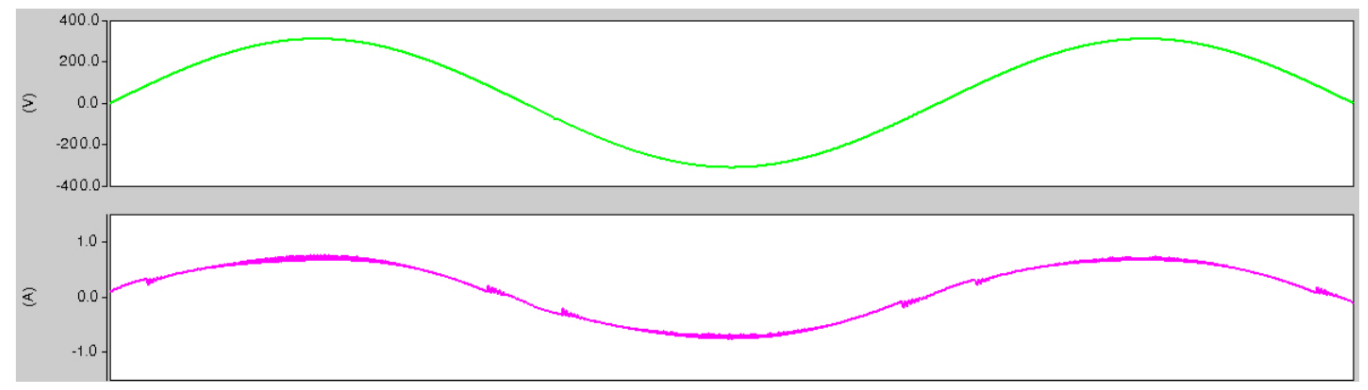

Figure 6. Input voltages and current of IBBC with VOTCS [Saber software]. 


\section{CONCLUSIONS}

In this paper, integrated BBC is presented and analyzed. It is composed of buck and boost converter. With COT control scheme, the input PF of the IBBC is low. In order to attain high input PF, VOT control scheme is proposed. Simulation results are presented for the verification of the analysis.

\section{REFERENCES}

Chen, F. Z., \& Maksimović, D. (2010). Digital control for improved efficiency and reduced harmonic distortion over wide load range in boost PFC rectifiers. IEEE Transactions on Power Electronics, 25(10), 2683-2692. https://doi.org/10.1109/TPEL.2010.2050702

IEG Standard, 61000-3. (n.d.). Electromagnetic compatibility (EMC). Limits for Harmonic Current Emissions (Equipment input current $\leq 16 \mathrm{~A}$ per phase).

García, O., Cobos, J. A., Prieto, R., Alou, P., \& Uceda, J. (2003). Single phase power factor correction: A survey. IEEE Transactions on Power Electronics, 18(3), 749-755. https://doi.org/10.1109/TPEL.2003.810856

Hwang, T. S., \& Park, S. Y. (2012). Seamless boost converter control under the critical boundary condition for a fuel cell power conditioning system. IEEE Transactions on Power Electronics, 27(8), 3616-3626. https://doi.org/10.1109/TPEL.2012.2185250

Langella, R., Testa, A., \& Alii, E. (2014). IEEE recommended practice and requirements for harmonic control in electric power systems. IEEE Std. 519-2014. IEEE.

Liu, X., Wan, Y., He, M., Zhou, Q., \& Meng, X. (2020). Buck-Type Single-Switch Integrated PFC Converter With Low Total Harmonic Distortion. IEEE Transactions on Industrial Electronics, 6. http://doi.org/10.1109/TIE.2020.3007121

Liu, X., Xu, J., Chen, Z., \& Wang, N. (2014). Single-inductor dual-output buck-boost power factor correction converter. IEEE transactions on Industrial electronics, 62(2), 943952. https://doi.org/10.1109/TIE.2014.2334659 
Mahdavi, M., \& Farzanehfard, H. (2010). Bridgeless SEPIC PFG rectifier with reduced components and conduction losses. IEEE Transactions on Industrial Electronics, 58(9), 4153-4160. https://doi.org/10.1109/TIE.2010.2095393

Memon, A. H., \& Yao, K. (2018a). UPG strategy and implementation for buck-buck/ boost PF correction converter. IET Power Electronics, 11(5), 884-894. http://doi. org/10.1049/iet-pel.2016.0919

Memon, A. H., Baloach, M. H., Sahito, A. A., Soomro, A. M., \& Memon, Z. A. (2018b). Achieving High Input PF for CRM Buck-Buck/Boost PFC Converter. IEEE Access, 6, 79082-79093. http://doi.org/10.1109/ACGESS.2018.2879804

Memon, A. H., Memon, M. A., Memon, Z. A., \& Hashmani, A. A. (2019a). Critical Conduction Mode Buck-Buck/Boost Converter with High Efficiency. 3C Tecnología. Glosas de innovación aplicadas a la pyme. Edición Especial, Noviembre 2019, 201-219. http:// dx.doi.org/10.17993/3ctecno.2019.specialissue3.201-219

Memon, A. H., Memon, Z. A., Shaikh, N. N., Sahito, A. A., \& Hashmani, A. A. (2019b). Boundary conduction mode modified buck converter with low input current total harmonic distortion. Indian Fournal of Science and Technology, 12. https://doi. org/10.17485/ijst/2019/v12i17/144613

Memon, A. H., Nizamani, M. O., Memon, A. A., Memon, Z. A., \& Soomro, A. M. (2019c). Achieving High Input Power Factor for DCM Buck PFC Converter by Variable Duty-Cycle Control. 3C Tecnología. Glosas de innovación aplicadas a la pyme. Edición Especial, Noviembre 2019, 185-199. http://dx.doi.org/10.17993/3ctecno.2019. specialissue3.185-199

Memon, A. H., Noonari, F. M., Memon, Z., Farooque, A., \& Uqaili, M. A. (2020a). $\mathrm{AC} / \mathrm{DC}$ critical conduction mode buck-boost converter with unity power factor. $3 C$ Tecnología. Glosas de innovación aplicadas a la pyme. Edición Especial, Abril 2020, 93-105. http://doi.org/10.17993/3ctecno.2020.specialissue5.93-105

Memon, A. H., Pathan, A. A., Kumar, M., \& Sahito, A. J., \& Memon, Z. A. (2019d). Integrated buck-flyback converter with simple structure and unity power factor. 
Indian Fournal of Science and Technology, 12. https://doi.org/10.17485/ijst/2019/ v12i17/144612

Memon, A. H., Shaikh, N. N., Kumar, M., \& Memon, Z. A. (2019e). Buck-buck/boost converter with high input power factor and non-floating output voltage. International Journal of Computer Science and Network Security, 19(4), 299-304. http://paper.ijcsns. org/07_book/201904/20190442.pdf

Memon, A. H., Yao, K., Ghen, Q., Guo,J., \& Hu, W. (2016). Variable-on-time control to achieve high input power factor for a CRM-integrated buck-flyback PFC converter. IEEE Transactions on Power Electronics, 32(7), 5312-5322. http://doi.org/10.1109/ TPEL.2016.2608839

Memon, A. H., Samejo,J. A., Memon, Z. A., \& Hashmani, A. A. (2020b). Realization Of Unity Power Factor For Ac/Dc Boundary Conduction Mode Flyback Converter With Any Specific Turn's Ratio. Journal of Mechanics Of Continua And Mathematical Sciences, (spl6). 10.26782/jmcms.spl.6/2020.01.00014. https://doi.org/10.26782/ jmcms.spl.6/2020.01.00014

Memon, A. H., Shaikh, S. A., Memon, Z. A., Memon, A. A., \& Memon, A. A. (2020c). DGM Boost Converter with High Efficiency. Journal Of Mechanics Of Continua And Mathematical Sciences, (spl6). https://doi.org/10.26782/jmcms.spl.6/2020.01.00006

\section{Singh, B., Singh, B. N., Ghandra, A., Al-Haddad, K., Pandey, A., \& Kothari, D. P.} (2003). A review of single-phase improved power quality AC-DC converters. IEEE Transactions on industrial electronics, 50(5), 962-981. https://www.researchgate.net/ publication/3218193_A_review_of_single-phase_improved_power_quality_ACDG_converters

Wu, X., Yang,J., Zhang,J., \& Qian, Z. (2012). Variable on-time (VOT)-controlled critical conduction mode buck PFG converter for high-input AC/DC HB-LED lighting applications. IEEE Transactions on power Electronics, 27(11), 4530-4539. https://doi. org/10.1109/TPEL.2011.2169812 
Wu, X., Yang, J., Zhang, J., \& Xu, M. (2011). Design considerations of soft-switched buck PFC converter with constant on-time (COT) control. IEEE transactions on power electronics, 26(11), 3144-3152. https://doi.org/10.1109/TPEL.2011.2145391

Yang, F., Ruan, X., Yang, Y., \& Ye, Z. (2011). Interleaved critical current mode boost PFC converter with coupled inductor. IEEE Transactions on power electronics, 26(9), 2404-2413. https://doi.org/10.1109/TPEL.2011.2106165 